\title{
In-vitro effects of penicillin and clindamycin on the expression of Streptococcus pneumoniae capsule
}

\author{
I. BROOK and A. E. GOBER \\ Department of Pediatrics, Georgetown University and George Washington University Schools of Medicine, \\ Washington, DC, USA
}

\begin{abstract}
The effects of subinhibitory concentrations of penicillin or clindamycin were evaluated in $\mathbf{2 0}$ isolates of Streptococcus pneumoniae that were fully susceptible to penicillin and in 20 isolates that were of intermediate resistance. All isolates were capsulate and susceptible to clindamycin. After incubation in one-half of the MIC of clindamycin, $\mathbf{1 7 . 5 \%}$ of isolates retained a capsule, compared to $87.5 \%$ after incubation with one-half of the MIC of penicillin. Clindamycin appears to be superior to penicillin in reducing the expression of the capsule by $S$. pneumoniae.
\end{abstract}

\section{Introduction}

Streptococcus pneumoniae is a common cause of acute otitis media, pneumonia and meningitis. Isolates that exhibit intermediate susceptibility (MIC $0.1-1.0 \mathrm{mg} / \mathrm{L}$ ) or resistance $(\mathrm{MIC} \geqslant 2 \mathrm{mg} / \mathrm{L}$ ) to penicillin are increasingly prevalent and this complicates the management of infections caused by this organism [1]. Penicillinresistant $S$. pneumoniae may be resistant to other commonly prescribed antibiotics such as macrolides, some cephalosporins, and co-trimoxazole $[2,3]$, but most remain susceptible to clindamycin $[1,4]$.

The virulence of $S$. pneumoniae is partly attributed to its capsule which enables it to escape phagocytosis [5]. Interruption of capsule production in $S$. pneumoniae by the use of transposon mutagenesis renders the organism avirulent [6].

The influence of subinhibitory concentrations of penicillin and clindamycin on the expression of capsule by $S$. pneumoniae in vitro were investigated.

\section{Materials and methods}

$S$. pneumoniae strains were isolated from throat cultures of children seen in a paediatric clinic. The organisms were identified by characteristic colony

Received 5 Jan. 1996; revised version accepted 24 April 1996.

Corresponding author: Professor I. Brook, PO Box 70412, Chevy Chase, MD 20814-0412, USA. morphology and $\alpha$-haemolysis, confirmed by susceptibility to ethylhydrocupreine (Optochin ${ }^{(\mathbb{R})}$ ) and bile solubility; they were serotyped by a capsule swelling test with type-specific antiserum [7]. Routine screening of penicillin susceptibility was with a $1-\mathrm{mg}$ oxacillin disk on sheep blood-supplemented Mueller-Hinton agar. A strain was suspected of penicillin resistance when the zone of inhibition surrounding the disk measured $<20 \mathrm{~mm}$ after incubation for $24 \mathrm{~h}$ without $\mathrm{CO}_{2}$ at $35^{\circ} \mathrm{C}$. The MICs of penicillin (Penicillin-G, Bristol-Myers, Squibb, Princeton, NJ, USA) and clindamycin (The Upjohn Company, Kalamazoo, MI, USA) for each isolate were determined by the agar dilution method. Mueller-Hinton agar supplemented with sheep blood $5 \%$ was used, as recommended by the National Committee for Clinical Laboratory Standards [8]. The final inocula contained $\left(1 \times 10^{4}\right)-\left(3 \times 10^{4}\right)$ cfu/spot. The MIC was defined as the lowest drug concentration that prevented visible growth or yielded fewer than six discrete colonies.

To investigate the effect of subinhibitory concentrations of penicillin or clindamycin on capsule formation, isolates of $S$. pneumoniae $\left(10^{6} \mathrm{cfu}\right.$ in $\left.1 \mathrm{ml}\right)$ were incubated for $48 \mathrm{~h}$ at $37^{\circ} \mathrm{C}$ in $9 \mathrm{ml}$ of Todd-Hewitt broth medium that included antibiotic at 0.5 MIC. A tube without antimicrobial agents served as a control. The presence of a capsule was evaluated by electron microscopy after staining with ruthenium red [7]. The specimens were coded to prevent observer bias. An isolate was considered to be capsulate if a capsule was seen in $>75 \%$ of 500 bacterial cells.

Statistical analysis was done by the $\chi^{2}$ test and Fisher's exact test. 
Table 1. Effects of subinhibitory concentrations of penicillin and clindamycin on production of capsule by 40 strains of $S$. pneumoniae after incubation for $48 \mathrm{~h}$

\begin{tabular}{lccc}
\hline & \multicolumn{3}{c}{$\begin{array}{c}\text { Number of capsulate strains } \\
(\%)\end{array}$} \\
\cline { 2 - 4 } after incubation with \\
\hline Suceptibility to penicillin & Penicillin & Clindamycin & Saline \\
\hline Fully susceptible $(\mathrm{n}=20)$ & $17(85)$ & $3(15)^{*}$ & $20(100)$ \\
Intermediate resistance $(\mathrm{n}=20)$ & $18(90)$ & $4(20)^{*}$ & $20(100)$ \\
\hline
\end{tabular}

${ }^{*} p<0.05$ compared with penicillin results.

\section{Results}

Forty isolates of $S$. pneumoniae were included in the study; 20 were fully susceptible to penicillin and 20 exhibited an intermediate level of resistance. All isolates were susceptible to clindamycin (MIC $0.025-$ $0.05 \mathrm{mg} / \mathrm{L})$.

Twelve isolates were serotype 6 (seven susceptible and five intermediately resistant to penicillin), eight were serotype 14 (three susceptible and five intermediate), 10 were serotype 19 (six susceptible and four intermediate), and 10 were serotype 23 (five susceptible and five intermediate).

All isolates were capsulate when grown without antibiotics. Incubation with clindamycin significantly reduced the prevalence of capsule formation, as compared with penicillin in both penicillin susceptible or intermediately resistant isolates (Table 1).

\section{Discussion}

In this study, exposure of $S$. pneumoniae to clindamycin at 0.5 MIC commonly suppressed the formation of the capsule, whereas a subinhibitory concentration of penicillin was less effective in this respect. The inability of penicillin to suppress capsule formation has been demonstrated previously in experiments in which the concentration of $S$. pneumoniae in the growth medium was $>10^{6}-10^{7} \mathrm{cfu} / \mathrm{ml}$ [9].

Similar suppressive effects of subinhibitory concentrations of clindamycin on capsule formation have been observed in $S$. pyogenes [10] and Staphylococcus aureus [11]. In the latter study, phagocytosis of Staph. aureus by macrophages was enhanced [11].

The growing resistance of $S$. pneumoniae to penicillin and other antimicrobial agents necessitates the use of alternative effective drugs. Most intermediately resistant $S$. pneumoniae isolates are currently susceptible to clindamycin $[1,4]$ and suppression of capsule formation is an additional beneficial quality that might enhance eradication of the organism. Concentrations of clindamycin in the middle ear [12] are c. 100 times higher than the $\mathrm{MIC}_{90}$ of penicillin-resistant $S$. pneumoniae. Clindamycin is effective in the therapy of otitis media caused by penicillin-susceptible and penicillin-resistant Staph. aureus, Staph. epidermidis [13], S. pneumoniae and anaerobic bacteria [14]. Further studies are warranted to evaluate the clinical efficacy of clindamycin in other $S$. pneumoniae infections.

\section{References}

1. Nelson CT, Mason EO, Kaplan SL. Activity of oral antibiotics in middle ear and sinus infections caused by penicillin-resistant Streptococcus pneumoniae: implications for treatment. Pediatr Infect Dis J 1994; 13: 585-589.

2. Klugman KP, Koornhof HJ. Drug resistance patterns and serogroups or serotypes of pneumococcal isolates from cerebrospinal fluid or blood, 1979-1986. J Infect Dis 1988; 158: $956-964$.

3. Appelbaum PC. Antimicrobial resistance in Streptococcus pneumoniae: an overview. Clin Infect Dis 1992; 15: 77-83.

4. Block SL, Harrison CJ, Hedrick JA et al. Penicillin-resistant Streptococcus pneumoniae in acute otitis media: risk factors, susceptibility patterns and antimicrobial management. Pediatr Infect Dis $J$ 1995; 14: 751-759.

5. Musher DM, Johnson B, Watson DA. Quantitative relationship between anticapsular antibody measured by enzyme-linked immunosorbent assay or radioimmunoassay and protection of mice against challenge with Streptococcus pneumoniae serotype 4. Infect Immun 1990; 58: 3871-3876.

6. Watson DA, Musher DM. Interruption of capsule production in Streptococcus pneumoniae serotype 3 by insertion of transposon Tn916. Infect Immun 1990; 58: 3135-3138.

7. Murray PR, Baron EJ, Pfaller MA, Tenover FC, Yolken RH (eds). Manual of clinical microbiology, 6th edn. Washington, DC, American Society for Microbiology, 1995.

8. National Committee for Clinical Laboratory Standards. Methods for dilution antimicrobial susceptibility tests for bacteria that grow aerobically. M7-A3. Villanova, PA, National Committee for Clinical Laboratory Standards, 1995.

9. Holloway Y, Boersma WG, Kuttschrütter H, Snijder-JAM. Detection of pneumococcal capsular antigen in the presence of penicillin in vitro. Scand J Infect Dis 1993; 25: 317-322.

10. Brook I, Gober AE, Leyva F. In vitro and in vivo effects of penicillin and clindamycin on expression of group A betahemolytic streptococcal capsule. Antimicrob Agents Chemother 1995; 39: 1565-1568.

11. Milatovic D, Braveny J, Verhoef J. Clindamycin enhances opsonization of Staphylococcus aureus. Antimicrob Agents Chemother 1983; 24: 413-417.

12. Yokoi H, Murahashi K, Yanagita N, Deguchi K. Study of tissue concentration of clindamycin-2-phosphate and its clinical usefulness. Pract Otol (Kyoto) 1985; 78: 2891-2896.

13. Feigin RD, Keeney RE, Nusrala J, Shackleford PG, Lins RD. Efficacy of clindamycin therapy for otitis media. Arch Otolaryngol 1973; 98: 27-31.

14. Brook I. Management of chronic suppurative otitis media: superiority of therapy effective against anaerobic bacteria. Pediatr Infect Dis J 1994; 13: 188-193. 